\title{
The influence of street-scale built environment on transportation mode choice of travelers around metro stations
}

\author{
Yanan $\mathrm{Liu}^{1 *}$ \\ ${ }^{1}$ Eindhoven University of Technology, Department of the Built Environment, 5600 MB Eindhoven, the Netherlands
}

\begin{abstract}
To understand the determinants of transportation mode choice of travelers around metro stations, more and more built environment attributes have been studied and shown significant results. This study focuses on the impacts of street-scale built environment on the travelers around the metro stations. 754 trips stemming from 309 respondents were collected around Yingkoudao metro station in Tianjin, China. A multinomial logit model was estimated to predict transportation mode choice to/from the study area as a function of socio-demographic information, trip characteristics, and street-scale built environment attributes (including land use mix, road width, the shortest distance to the station, sidewalk width, number of lamps, greenery area, and traffic light presence) along the shortest route between the Yingkoudao metro station and the origin/destination around the station for the choice of metro+walk. The results show that not only the socio-demographic characteristics, but also the distance to the station, land use mix, and number of lamps significantly influence the choice of metro+walk.
\end{abstract}

\section{Introduction}

To enhance metro use, it is important to understand transportation mode choice [1]. Various factors affect metro use. Besides attributes of the railway system itself (e.g., station spacing, service, etc.) [2, 3], employment, residential density, and distance to metro stations are commonly used predictors of ridership [4,5,6,7]. In addition, several studies provided evidence of the impact of the built environment around the transit station on metro use, including land use mix, floor area of buildings, feeder bus lines, bicycle park-and-ride spaces $[7,8,9,10,11]$, and road network characteristics (connectivity between the station and the destinations around the station, intersection density, and vehicle lane number) $[12,13]$. Most studies on the influence of the built environment on the choice of metro focused on meso-level transportation-related facilities and land use patterns using regression models, except for Jun et al. [12] who used a discrete choice model with the sum of boarding and alighting as the dependent variable. However, other street-scale built environment variables may influence metro use [14]. To study their effect, individual-level trips and advanced quantitative methods are needed rather than the aggregate models that have been employed in the above direct ridership analyses.

This study will explore the impact of the street-scale built environment around the metro station on transportation mode choice. A discrete choice model based on individual-level trip data will be estimated to analyse the quantitative relationship between street-scale built environment attributes and transportation mode choice in the metro station area. The data used for analysis are summarized in Section 2. The generation of choice sets and model specification are discussed in Section 3. Results are reported and interpreted in Section 4. Finally, conclusions are drawn in Section 5.

\section{Data collection}

\subsection{Captions/numbering}

The questionnaire included two parts: sociodemographic information and information about trip characteristics and transportation mode choice. The socio-demographic information concerned age, gender, car ownership. The second part of the questionnaire collected details of trips either originating from the study area to outside the study area or in a reverse direction. Collected details included departure time, arrival time, origin, destination, trip purpose, carry luggage, travel party, and transportation mode. Trip purposes were distinguished into going to work, going home, non-daily shopping, going to school/university, visit others, pick up children, going to grocery store/supermarket, recreation (catering, entertainment, park, public facilities, etc.), and going to official service (bank, government, post, etc.). Travel party included alone, partner, children (under 18 years old), friends or relatives (18 to 65 years old or older than 65 years of age), and other. The transportation mode options were metro, bus, walk, car, personal bike, shared bike, e-bike, taxi, motorbike, and other.

If a respondent did not use public transportation, the routes for walking, biking, car, and taxi were not

\footnotetext{
*Yanan Liu: liuuynup@outlook.com
} 
collected but calculated as the shortest route. If a respondent took the metro/bus as their main transportation mode, some extra trip characteristics were collected: transportation mode to/from the station, travel time from the origin to the station, waiting time for metro/bus, transportation mode to the destination from the station, and travel time from the station to the destination.

\subsection{Study area and survey administration}

A "typical" metro station in a second-tier Chinese city was selected as the study area: Yingkoudao station in the city center of Tianjin. The study area is an area of $2000 * 2000$ squared meters around Yingkoudao metro station, which is one of the busiest metro stations in Tianjin. The survey was administered in the whole study area, not only in the blocks immediately surrounding the metro station. Twelve university students were recruited and trained to conduct the face-to-face interviews that took place in September 2018 over a total period of 25 days and for a maximum of 8 hours per day. A stratified spatial sample was used based on the population and employment density in each block. Respondents were randomly selected in each block. Those who completed the questionnaire were given a small gift. The completed questionnaires were checked daily by the person who was in charge of the survey. The response rate was about $91 \%$. A total of 401 respondents, who reported 1059 trips, completed the questionnaire. After screening each reported trip, 754 trips stemming from 309 respondents with full trip information were used for model estimation. The deleted trips were either trips with missing information or trips that did not originate or end in the study area.

\subsection{Sample characteristics}

The distribution of the socio-demographics of the respondents is shown in Table 1. The age of the sample is younger compared to the city data from the Tianjin Statistical Bureau, which may be explained because the city center attracts more young people who live and/or work there.

The sample has slightly more females than males. Respondents have a higher education level than the general population of Tianjin which may be caused by the universities located in or close to the study area. More than half of the respondents have one or more cars in their family. As shown in Table 2, metro+walk is the most frequently chosen transportation mode. The distribution of trip purposes, shown in Table 3, suggests that more than half of the trips are for going home or shopping.

Table 1. Distribution of socio-demographics

\begin{tabular}{cccc}
\hline Variables & Category & \multicolumn{2}{c}{ Distribution } \\
\hline Age & 10 to 17 & 28 & $9.1 \%$ \\
& 18 to 29 & 160 & $51.8 \%$ \\
& 30 to 39 & 46 & $14.9 \%$ \\
& 40 to 49 & 40 & $12.9 \%$ \\
\hline
\end{tabular}

\begin{tabular}{cccc}
\hline \multirow{4}{*}{ Gender } & 50 to 59 & 16 & $5.2 \%$ \\
& 60 to 73 & 19 & $6.1 \%$ \\
Car ownership & Male & 141 & $45.6 \%$ \\
& Female & 168 & $54.4 \%$ \\
& Owns car & 172 & $55.7 \%$ \\
& Does not own a car & 137 & $44.3 \%$ \\
\hline
\end{tabular}

Table 2. Distribution of transportation mode

\begin{tabular}{ccc}
\hline Transportation mode & Number of trips & Percentage \\
\hline Metro+walk & 202 & $26.8 \%$ \\
Bus & 115 & $15.3 \%$ \\
Walk & 99 & $13.1 \%$ \\
Bike & 144 & $19.1 \%$ \\
Car & 90 & $11.9 \%$ \\
Taxi & 104 & $13.8 \%$ \\
Total & 754 & $100 \%$ \\
\hline
\end{tabular}

Table 3. Distribution of trip purpose

\begin{tabular}{lll}
\hline Trip purpose & Number of trips & Percentage \\
\hline Work & 143 & $19.0 \%$ \\
Home & 301 & $39.9 \%$ \\
Shopping & 258 & $34.2 \%$ \\
Other & 52 & $6.9 \%$ \\
Total & 754 & $100 \%$ \\
\hline
\end{tabular}

\subsection{Street-scale built environment variables}

The built environment data used in this model are listed in Table 4. The built environment variables used in the mode choice model include land use mix, FAR, road width, distance to the metro station, sidewalk width, number of lamps, greenery area, presence of traffic lights, and building frontage. The calculation of land use mix is based on the equation of Liu, Yang, Timmermans, and de Vries [15].

Table 4. Built environment attributes at the route level

\begin{tabular}{|c|c|c|}
\hline Estimated variables & Description & $\begin{array}{c}\text { Units at route- } \\
\text { level }\end{array}$ \\
\hline $\begin{array}{l}\text { Distance to the } \\
\text { metro station }\end{array}$ & $\begin{array}{l}\text { Sum of the variable } \\
\text { across all links of } \\
\text { the route }\end{array}$ & $\begin{array}{l}\text { A continuous } \\
\text { number in } \\
\text { meters }\end{array}$ \\
\hline Street greenery area & & $\begin{array}{l}\text { A continuous } \\
\text { number in } \mathrm{m}^{2}\end{array}$ \\
\hline Number of lamps & & A continuous \\
\hline Sidewalk width & $\begin{array}{l}\text { Sum of the variable } \\
\text { across all links, } \\
\text { divided by the total } \\
\text { length of all links }\end{array}$ & $\begin{array}{l}\text { number } \\
\text { A continuous } \\
\text { number in } \\
\text { meters }\end{array}$ \\
\hline $\begin{array}{l}\text { Number of traffic } \\
\text { lights }\end{array}$ & & $\begin{array}{l}\text { A continuous } \\
\text { number between } \\
0 \text { and } 2\end{array}$ \\
\hline Road width & & $\begin{array}{l}\text { A continuous } \\
\text { number in } \\
\text { meters }\end{array}$ \\
\hline Land use mix & $\begin{array}{l}\text { The diversity of } \\
\text { land use classes and }\end{array}$ & $\begin{array}{l}\text { A continuous } \\
\text { number between }\end{array}$ \\
\hline
\end{tabular}




\begin{tabular}{lll}
\hline & $\begin{array}{l}\text { types on both sides } \\
\text { of the route }\end{array}$ & 0 and 1 \\
Total "building & A continuous \\
front length" across & number between \\
& $\begin{array}{l}\text { links divided by } \\
\text { route length }\end{array}$ & 0 and 2 \\
The floorage ratio & $\begin{array}{l}\text { Total "building } \\
\text { area" across links } \\
\text { divided by total } \\
\text { (FAR) }\end{array}$ & $\begin{array}{l}\text { A continuous } \\
\text { number } \\
\text { on each route }\end{array}$ \\
& each link & \\
& & \\
\hline
\end{tabular}

\section{Methodology}

The analysis focused on the influence of street-scale built environment around the metro station on transportation mode choice of people who travel in/out the study area. Metro+walk, bus, car, walk, bike, and taxi are included in the set of available transportation modes. The street-scale built environment attributes are only considered in the specification of the utility of the metro+walk choice alternative. More specifically, the street-scale built environment data were generated for the shortest route between Yingkoudao metro station and the origin/destination in the study area. A multinomial logit model was estimated, using maximum likelihood, to predict transportation mode choice. The probability that individual $n$ chooses mode $k$ equals:

$$
P_{k n}=\frac{\exp \left(V_{k n}\right)}{\sum_{l \in C} \exp \left(V_{l n}\right)} \quad n=1, \ldots, N
$$

where, $V k n$ is the utility of transportation mode $\mathrm{k}$ of individual $n, V l n$ is the utility of transportation mode $l$ in choice set $C$ of individual $n$.

The utility function of each transportation mode is a linear additive function of mode attributes, trip purpose and socio-demographic variables. As indicated, built environment attributes were added to the metro+walk option. All socio-demographic attributes and trip purpose were effect-coded. Age was categorized into three levels, 10 to 30 years old, 31 to 50 years old, and 51 to 65 years old.

\section{Results}

The estimation results are shown in Table 5. McFadden's pseudo-rho-squared is 0.524 , and the adjusted rho-squared is 0.464 , which suggests a good model fit. Table 5 shows that for metro+walk, the estimated effects for travel time, having a car, trip purposes going home and shopping, land use mix, distance to station and building frontage are significant. It indicates that respondents who choose metro+walk are influenced by not only travel but also street-scale built environment attributes. The negative sign of time indicates that a trip with a longer time will decrease the probability of choosing metro+walk. The negative sign of the variable having a car suggests that respondents who have a car have a lower probability of choosing metro+walk. The positive signs of land use mix and building frontage imply that more land use mix and building frontage increase the probability of choosing transportation mode metro+walk. The negative sign of distance to the metro station indicates that the probability of choosing transportation mode metro+walk decreases with increasing distance to the metro station.

As for bus, the estimated effects for having a car, 10 to 30 years old, going home trip purpose, and shopping are negative and significant, while the age category 51 to 65 years is positive and significant. It indicates that the elderly prefers the bus. Respondents who are going home or shopping do not prefer the bus. In the case of walking, the estimated effects for travel time and an age between 10 and 30 years old are negative and significant, while the effect for age between 51 and 65 is positive and significant. It indicates that older respondents prefer walking more than younger respondents do. Walking is less likely if the route takes longer. For bike, the estimated effects are significant and negative for travel time, female, and trip purpose shopping. Finally, the estimated effects for car are significantly negative for females, 10 to 30 years old, and shopping, but positive and significant for having a car.

Table 5. Estimation results of transportation mode choice model

\begin{tabular}{lllllll}
\hline Transportation mode & Metro+walk & Bus & Walk & Bike & Car & Taxi \\
\hline \multirow{3}{*}{ Constant } & Parameter & Parameter & Parameter & Parameter & Parameter & Parameter \\
& 2.237 & $1.390^{* * *}$ & $3.658^{* * *}$ & $1.895^{* * *}$ & $-1.352^{* *}$ & 0 \\
Travel time & $(1.23)$ & $(2.64)$ & $(9.24)$ & $(5.40)$ & $(-2.29)$ & \\
& $-0.053^{* * *}$ & 0.005 & $-0.077^{* * *}$ & $-0.076^{* * *}$ & 0.006 & 0 \\
Cost & $(-3.84)$ & $(0.68)$ & $(-8.26)$ & $(-5.68)$ & $(0.21)$ & \\
& 0.127 & -0.358 & - & - & 0.094 & 0 \\
Female & $(0.87)$ & $(-1.63)$ & & & $(0.98)$ & \\
& 0.138 & -0.125 & -0.188 & $-0.364^{* *}$ & $-0.519^{* * *}$ & 0 \\
Male & $(0.98)$ & $(-0.88)$ & $(-1.15)$ & $(-2.57)$ & $(-3.01)$ & \\
Have a car & -0.138 & 0.125 & 0.188 & 0.362 & 0.519 & 0 \\
& $-0.390^{* * *}$ & $-0.458^{* * *}$ & 0.066 & -0.110 & $0.790^{* * *}$ & 0 \\
Don't have a car & $(-2.73)$ & $(-3.10)$ & $(0.38)$ & $(-0.76)$ & $(3.21)$ & \\
10 to 30 years old & 0.390 & 0.458 & -0.066 & 0.110 & -0.790 & 0 \\
& -0.250 & $-0.504^{* *}$ & $-1.192 * * *$ & -0.294 & $-0.889 * * *$ & 0 \\
31 to 50 years old & $(-0.94)$ & $(-2.18)$ & $(-4.60)$ & $(-1.17)$ & $(-3.13)$ & 0 \\
\hline
\end{tabular}




\begin{tabular}{|c|c|c|c|c|c|c|}
\hline 51 to 65 years old & $\begin{array}{l}-0.058 \\
(-0.13)\end{array}$ & $\begin{array}{l}0.701 * * \\
(2.03)\end{array}$ & $\begin{array}{l}1.242 * * * \\
(3.25)\end{array}$ & $\begin{array}{l}-0.259 \\
(-0.63)\end{array}$ & $\begin{array}{l}-0.328 \\
(-0.71)\end{array}$ & 0 \\
\hline Trip purpose: home & $\begin{array}{l}-0.713^{* * * *} \\
(-2.99)\end{array}$ & $\begin{array}{l}-0.727 * * * \\
(-2.95)\end{array}$ & $\begin{array}{l}-0.320 \\
(-1.14)\end{array}$ & $\begin{array}{l}-0.019 \\
(-0.08)\end{array}$ & $\begin{array}{l}-0.321 \\
(-1.20)\end{array}$ & 0 \\
\hline Trip purpose: shopping & $\begin{array}{l}-0.575^{* *} \\
(-2.38)\end{array}$ & $\begin{array}{l}-0.823^{* * * *} \\
(-3.26)\end{array}$ & $\begin{array}{l}-0.405 \\
(-1.45)\end{array}$ & $\begin{array}{l}-0.675^{* * * *} \\
(-2.63)\end{array}$ & $\begin{array}{l}-1.040 * * * \\
(-3.27)\end{array}$ & 0 \\
\hline Trip purpose: other & $\begin{array}{l}0.212 \\
(0.58)\end{array}$ & $\begin{array}{l}0.316 \\
(0.91)\end{array}$ & $\begin{array}{l}-0.043 \\
(-0.10)\end{array}$ & $\begin{array}{l}-0.718 \\
(-1.73)\end{array}$ & $\begin{array}{l}0.071 \\
(0.17)\end{array}$ & 0 \\
\hline Trip purpose: work & 1.076 & 1.234 & 0.768 & 1.413 & 1.290 & 0 \\
\hline Land use mix & $\begin{array}{l}3.793 * * \\
(2.39)\end{array}$ & & & & & \\
\hline FAR & $\begin{array}{l}0.085 \\
(0.63)\end{array}$ & & & & & \\
\hline Road width & $\begin{array}{l}-0.025 \\
(-0.82)\end{array}$ & & & & & \\
\hline Distance to the station & $\begin{array}{l}-0.002 * * * \\
(-2.91)\end{array}$ & & & & & \\
\hline Sidewalk width & $\begin{array}{l}0.231 \\
(1.15)\end{array}$ & & & & & \\
\hline Number of lamps & $\begin{array}{l}0.011 \\
(0.89)\end{array}$ & & & & & \\
\hline Street greenery $/ 1000$ & $\begin{array}{l}-0.584 \\
(-1.57)\end{array}$ & & & & & \\
\hline Traffic lights presence & $\begin{array}{l}-0.065 \\
(-0.17)\end{array}$ & & & & & \\
\hline Building frontage & $\begin{array}{l}2.232 * * * \\
(5.75)\end{array}$ & & & & & \\
\hline
\end{tabular}

Note: $t$-value in parentheses. $* * *$ indicates significant values at the $1 \%$ level. $* *$ indicates significant values at the $5 \%$ level.

\section{Conclusions and discussion}

This chapter reported the results of an analysis of the impact of street-scale built environment attributes on metro use in the Yingkoudao metro station area, Tianjin, China. A discrete transportation mode choice model was estimated. Revealed transportation mode choice data of respondents around this metro station were used to quantify the effects of selected factors on people's transportation mode choice. It has been found that time, gender, age, car ownership, and trip purposes influence the choice of transportation mode. Not only travel and individual characteristics but also street-scale built environment attributes have a significant influence on the metro+walk mode. However, built environment attributes only seem to have a modest effect. Only building frontage and land use mix around the metro station have a positive influence on the choice of metro+walk. The distance to the station has a negative influence on the choice of this transportation mode.

The results of gender and trip purpose are consistent with Buehler[16] in the USA, who also concluded that males prefer biking more than females do, and that shopping has a negative effect on the probability of choosing public transport, walking, and biking. The finding that younger people (10 to 30 years old) do not prefer to travel by bus is inconsistent with Verhoeven, Arentze, Timmermans, and van der Waerden[17]. These inconsistencies may reflect differential ownership in combination with potential problems of revealed preference data in eliciting true underlying preferences.
Limitations in available data allowed us to include built environment attributes only for the choice of metro+walk. The built environment characteristics may also influence walk and bike in this transportation mode choice model. Consequently, the estimated influence of the built environment attributes in this model may be biased. Other possible modes on the access/egress trips of metro stations such as metro+bike and bus were not included in this model. The reason is that only very few (less than 10) samples were caught in the survey. The small number of samples caused errors in the model estimation.

\section{References}

1. Chan, S., Miranda-Moreno, L. A station-level ridership model for the metro network in Montreal, Quebec. Canadian Journal of Civil Engineering, 40(3), 254-262 (2013)

2. Brown, J., Hess, D. B., Shoup, D. Unlimited access. Transportation, 28(3), 233-267. (2001)

3. Kuby, M., Barranda, A., Upchurch, C. Factors influencing light-rail station boardings in the United States. Transportation Research Part A: Policy and Practice, 38(3), 223-247. (2004)

4. Cardozo, O. D., García-Palomares, J. C., Gutiérrez, J. Application of geographically weighted regression to the direct forecasting of transit ridership at station-level. Applied Geography, 34, 548-558. (2012) 
5. Cristaldi, F. Commuting and gender in Italy: A methodological issue. The Professional Geographer, 57(2), 268-284. (2005)

6. Giuliano, G. Travel, location and race/ethnicity. Transportation Research Part A: Policy and Practice, 37(4), 351-372. (2003)

7. Gutiérrez, J., Cardozo, O. D., García-Palomares, J. C. Transit ridership forecasting at station level: An approach based on distance-decay weighted regression. Journal of Transport Geography, 19(6), 1081-1092. (2011)

8. Filion, P. Suburban mixed-use centres and urban dispersion: What difference do they make? Environment and Planning A: Economy and Space, 33(1), 141-160. (2001)

9. Gan, Z., Yang, M., Feng, T., Timmermans, H. J. P. Examining the relationship between built environment and metro ridership at station-to-station level. Transportation Research Part D: Transport and Environment, 82, 102332. (2020)

10. Shao, Q., Zhang, W., Cao, X., Yang, J., Yin, J.. Threshold and moderating effects of land use on metro ridership in Shenzhen: Implications for TOD planning. Journal of Transport Geography, 89, 102878. (2020)

11. Zhao, J., Deng, W., Song, Y., Zhu, Y. What influences metro station ridership in China? Insights from Nanjing. Cities, 35, 114-124. (2013)

12. Jun, M. J., Choi, K., Jeong, J. E., Kwon, k. h., Kim, H. J. Land use characteristics of subway catchment areas and their influence on subway ridership in Seoul. Journal of Transport Geography, 48, 30-40. (2015)

13. Ozbil, A., Peponis, J. The effects of urban form on walking to transit. Paper presented at the 8th International Space syntax Symposium, Santiago de Chile: PUC. (2012)

14. Li, S., Lyu, D., Huang, G., Zhang, X., Gao, F., Chen, Y., Liu, X. (2020). Spatially varying impacts of built environment factors on rail transit ridership at station level: A case study in Guangzhou, China. Journal of Transport Geography, 82.

15. Liu, Y., Yang, D., Timmermans, H. J. P., de Vries, B. (2020). The impact of the street-scale built environment on pedestrian metro station access/egress route choice. Transportation Research Part D: Transport and Environment, 87, 102491.

16. Buehler, R. (2011). Determinants of transport mode choice: A comparison of Germany and the USA. Journal of Transport Geography, 19(4), 644-657. doi:https://doi.org/10.1016/j.jtrangeo.2010.07.005

17. Verhoeven, M., Arentze, T., Timmermans, H. J. P., van der Waerden, P. (2007). Examining temporal effects of lifecycle events on transport mode choice decisions. International Journal of Urban Sciences, 11(1), 1-13. 